\title{
O luto e os espectros do marxismo e do socialismo
}

Ihering Guedes Alcoforado ${ }^{1}$

\begin{abstract}
Será sempre um erro não ler Marx. Isto é, também alguns outros - e para além da "leitura" ou da "discussão" acadêmica. Cada vez mais será um erro, uma falta de responsabilidade teórica, filosófica, política ... Não haverá futuro sem isto. Não sem Marx, não há futuro sem Marx, sem a memória e sem a herança de Marx, de seu gênio, de um ao menos de seus espíritos. Pois esta será nossa hipótese, ou antes, nosso parti-pris: há mais de um, deve haver mais de um. ${ }^{2}$
\end{abstract}

\section{INTRODUÇ̃̃o}

As condições necessárias a reorganização do movimento socialista não têm emergido com a crise do Estado de Bem Estar e a ascensão das organizações políticas que adotam estratégias discursivas apoiadas no legado socialista; muito pelo contrário, o que se tem observado, com freqüência, com a promoção das organizações de inspiração socialista ao núcleo do poder, é uma renovação das estruturas de dominação apoiadas no mercado, através do que se revela a ausência de um framework socialista internalizado nestas organizações que permita não só estruturar a estratégia discursiva, mas principalmente equacionar e formular trajetórias adequadas a problemática vigente.

$--{ }_{--1-}$

1 Professor da Universidade Federal da Bahia.

2 Jaccques Derrida. Espectros de Marx: o estado da dívida, o trabalho do luto e a nova internacional. Rio de Janeiro, Relume Dumará, 1994, pp. 29-30.

84 O luto e os espectros do marxismo e do socialismo 
As crises do capitalismo permanecem, mas, agora, graças os avanços na compreensão do mercado que caracteriza a formação de uma nova ortodoxia econômica identificada como a BRICE Economics ${ }^{3}$, o equacionamento destas crises não mais se recorre ao planejamento central à Jan Tinbergen como alternativa do mercado, já que não mais se considera o mercado como o resultado de uma evolução espontânea e portador de falhas genéticas, mas como uma instituição que pode ser desenhada a partir dos direitos de propriedade.

No novo framework da BRICE economics, no qual identificamos vários espectros de Marx e do socialismo, o entendimento é que o deslocamento da intervenção estatal que se dava diretamente na economia, agora, passa a ser focada no mercado, entendido como uma instituição, isto é, o mercado se torna objeto de intervenção estatal a partir dos redesenhos dos direitos de propriedade, tal como propunham os socialistas e marxistas. E mais, esta intervenção dá-se a partir de uma orientação de mudança apoiada num processo de reconstrução da racionalidade no marco dialógico e de ampliação qualificada nos direitos de propriedade, de forma a incorporar os commons no núcleo nas teorias políticas públicas burguesas, configurando a apropriação dos insights originais emitidos pelos marxistas e socialistas, podados em sua radicalidade pelos formuladores das políticas burguesas

Em função do exposto acima, argumenta-se neste trabalho que a impotência dos marxistas diante desta nova realidade deve-se não ao fardo do legado do marxismo e do socialismo, mas da hipertrofia do interesse dos marxistas e socialista em alguns pontos da agenda, a exemplo da problemática do capital financeiro, a luta de classe e a transição para o socialismo, deixando de lado aspectos importantes, a exemplo da questão da crítica à racionalidade e aos regimes de propriedade.

3 Este nome foi proposto recentemente por Roger Koppl, em função desta nova ortodoxia ser caracterizada por cinco aspectos 1) racionalidade limitada (Bounded rationality), 2) agentes seguidores de regras (Rulefollowing agents, 3) análise institucional (Institutional analysis), 4) cognição (Cognition), e 5) evolução (Evolution), a qual tem entre seus principais representantes Ronald Coase, Geoff Hodgson, Douglass North, Vernon Smith, Brian Arthur, James Buchanan, David Colander, Herbert Simon, e F.A. Hayek, a maioria ganhadores do Prêmio Nobel de Economia, e todos comprometidos com uma compreensão mais nuançada dos mercados do que a difundida através dos livros textos. 0 que, visto pela ótica das escolas de pensamento, nós temos a Economia Institucional (nova e Velha), Economia da complexidade (Complexity Economics), Economia Pós-Walraseana (Post Walrasian Economics), Economia Austríaca (Austrian Economics), Economia Política Institucional (Constitutional Political Economy) e a Economia Evolucionária (Evolutionary Economics).

cadernos cemarx, $n^{0} 2-2005 \quad 85$ 


\section{As Chaves de Leituras}

Este trabalho debruça-se sobre o paradoxo esboçado acima, isto é, a apropriação pela economia burguesa dos espectros do socialismo e do marxismo, visando fundamentar as soluções para suas próprias crises. E, adota como bússola, duas chaves de leitura inspirados na abordagem shakespeareana do legado marxista feita por Jacques Derrida, na qual destaco: i) a falta do "luto" e, em decorrência a ii) a negação dos "espectros" do marxismo e do socialismo.

Nesta direção, toma-se o "luto" no sentido derridareano, isto é, enquanto a ontologização dos restos da experiência do marxismo e do socialismo, tornandoos presentes através da identificação nos despojos, do perene; aqui, o recorte guiar-se-á pelo critério da necessidade de uma reapropriação incessante a) da crítica à racionalidade, da teoria dos direitos de propriedade de Marx, em especial da sua teoria da propriedade comunal, vinculada aos resultados do desenvolvimento tecnológico do capitalismo.

Enquanto que no âmbito dos espectros, a nossa chave de leitura vai na direção de desvelar uma manifestação dos espectros de Marx e do socialismo, no devir institucional das sociedades burguesas contemporâneas na esfera da racionalidade e do direito de propriedade, os dois despojos tratados no tópico anterior

O espectro marxista apropriado pela teoria social burguesa é tratado em duas partes. Na primeira, trata-se da tradição de crítica à razão, da qual Marx é um dos expoentes, mostrando que enquanto o pensamento social burguês contemporâneo já assimila os espectros marxistas evocados pela Escola de Frankfurt, por exemplo, através da incorporação da racionalidade comunicativa de J. Habermas, no novo planejamento e nas novas políticas sociais, o pensamento socialista, em boa parte, ainda patina em cima de uma racionalidade técnica instrumental. Na segunda parte, mostra-se que esta apropriação dos espectros do marxismo, pelo pensamento social burguês contemporâneo, também dá-se no âmbito da teoria do direito de propriedade marxista, a qual é inserida no núcleo duro de sua teoria social; e, ainda avança, no varejo, ao tomar os commons, originalmente teorizados por Marx, como a referência básica da maior parte das novas políticas públicas.

Em resumo, a nossa leitura do legado marxista e socialista tenta recolocar duas ferramentas básicas ao movimento socialista no século XXI: planejamento e formulação de políticas públicas, apropriando-se criticamente dos novos mecanismos institucionais do capitalismo, usados para desqualificar o legado marxista e socialista, po-

86 O luto e os espectros do marxismo e do socialismo 
rém expressões emblemáticas dos espectros de Marx e do socialismo, normalmente não captadas pelos seus herdeiros, por falta do luto ${ }^{4}$.

\section{OBJetIVOS}

O trabalho busca, portanto, o acerto de contas com uma fração dos restos da experiência do marxismo e do socialismo, tendo em mente o restabelecimento dos pontos esquecidos da agenda dos mesmos, como um passo na reconstrução do movimento socialista do século XXI. Em função disto, o objetivo é mostrar que a retomada dos pontos esquecidos (pelos marxistas, mas não pelos liberais) da agenda de Marx e dos socialistas é mais do que suficiente para estabelecer os contornos de um quadro conceitual necessário à reconstrução do socialismo enquanto uma alternativa de re-ordenamento da sociedade moderna que tem, tanto como meio, como fim, não o individuo isolado, mas os grupos sociais. Em outras palavras, o objetivo é apontar a possibilidade de que uma alternativa de reconstrução do socialismo está na retomada do espírito de Marx e do socialismo manifesto nos espectros apropriados pelo capitalismo, i) da tradição de crítica à racionalidade e sua manifestação operacional, no planejamento, e ii) à tradição de crítica aos direitos de propriedade.

\section{Metodologia}

Inicialmente, trata-se o fato de Marx ser um marco na tradição de crítica à razão que envolve entre outros Kant, Hegel, o próprio Marx, e, mais recentemente, a Escola de Frankfurt, de forma a patentear, tal como na epígrafe que, a obra de Marx é um "resto perene" da experiência do marxismo. Ou seja, argumenta-se que a ontologização dos restos associados a crítica da razão e da propriedade, do marxismo e do socialismo, permite-nos reassumir o legado de uma tradição comprometida com a promoção da sociedade humana, na direção da recuperação da sua humanidade. Ainda neste tópico, aponta-se que esta tradição ainda tem energias suficiente para sua reconstrução, como demonstram as sucessivas gerações da Escola de Frankfurt. Neste âmbito, os espectros marxistas são corporificados, por exemplo, na teoria do pla-

$-\cdots$

4 Derrida, op. cit., pp. 24, 41 e 51.

cadernos cemarx, $\eta ^ { 0 } 2 - 2 0 0 5 \longdiv { 8 7 }$ 
nejamento crítico de J. Forester, a qual já não mais maneja uma racionalidade técnica, mas apóia-se numa racionalidade comunicativa; na teoria dos novos movimentos sociais de K. Eder que não mais se orienta pela luta distributiva, mas por uma luta identitária e emancipatória 5 .

O resgaste do "resto perene" tem continuidade na teoria dos direitos de propriedade, um ponto da agenda marxista esquecida, que precisa ser resgatada já que, no momento, difunde-se pelo mundo como fundamental para o desenho das novas instituições necessárias ao desenvolvimento, só que podada da radicalidade marxista ${ }^{6}$.

Já a retomada de um ponto de vista racial, dos espectros marxistas e socialistas apropriados pelo planejamento e políticas publicas burguesas depois de extirpada sua radicalidade, será intentada a partir da atualização crítica da agenda socialista no âmbito da racionalidade e dos direitos de propriedade, de maneira a re-introduzir no planejamento e nas políticas públicas a energia utópica vocalizada por Marx.

\section{CONCLUSÃo}

Na conclusão, leva-se em conta o exposto acima para justificar nosso entendimento que, uma condição necessária à reconstrução do socialismo dá-se através do reavivamento e reapropriação dos espectros de Marx e do socialismo, atualmente, em posse do pensamento social burguês.

$---\cdots$

5 J. Forester, "Critical theory and planning practice". In: Journal of the American Institute of Planners, p. 275286. Klaus Eder, "The New Social Movement: moral, crusade, political pressure group, or social movements ?" In: Social Resarch, v. 52, no 4, 1985, pp. 869-890.

6 Steve Pejovich, "Karl Marx, Property Rights and the School and the Process of Social Change". In: Kiklos International Review for Social Sciences, v. 35, no 3, 1982, pp. 383-397. Thráinn Eggertsson, Property Rights, Agency and Economic Organization in Economic Behavior and Institutions. New York, Cambridge University Press, 1990 (Cambridge Survey of Econmic Literature Series).

88 O luto e os espectros do marxismo e do socialismo 